\title{
Changes in feeding and crawling rates of Hydrobia truncata (Prosobranchia: Hydrobiidae) in response to sedimentary chlorophyll-a and recently egested sediment
}

\author{
Valery E. Forbes \& Glenn R. Lopez
}

Marine Sciences Research Center, State University of New York, Stony Brook, New York 11794, USA

\begin{abstract}
Experiments combining fluorescent particle tracer techniques with time-lapse video recording demonstrated that the gastropod Hydrobia truncata decreases crawling rate on patches rich in chlorophyll- $a$, while maintaining a constant feeding rate as sedimentary chlorophyll- $a$ content varies. In contrast, $H$. truncata decreases feeding rate but does not change crawling rate upon encounter with patches of recently egested sediment. Depression of feeding rate is less pronounced if the egested material is enriched in chlorophyll-a. For deposit feeders inhabiting highly reworked sediments, the majority of available material may consist of sediment that has been recently egested. For an animal that responds negatively to recently egested sediment, the pool of material available for ingestion may be much reduced. The ability to independently control rates of energy input and expenditure in response to rapidly changing environmental conditions may enable an organism to control net energy gain over short time periods.
\end{abstract}

\section{INTRODUCTION}

The relationship between food quality and feeding rate is of special concern in the study of deposit feeders, a group of invertebrates whose food resources (bacteria, microalgae, and detrital material) are considerably diluted by non-digestible mineral grains. Mobile deposit feeders can respond to variations in food quality not only by altering feeding rate, but by seeking out areas of high food availability. For example, the sand fiddler crab Uca pugilator moves through its habitat when substratum food levels are reduced (Robertson et al. 1980). The mud-dwelling gastropods Aporrhais pes-pelecani and Turritella communis abandon their burrows and move to a new area in response to local food depletion (Newell 1979). However, moving requires energy, thus there is likely to be a tradeoff between the advantages gained by crawling in search of food-rich patches and those gained by staying in place and feeding on locally available material.

Contribution No. 537 from the Marine Sciences Research Center

(C) Inter-Research/Printed in F. R. Germany
For gastropods the metabolic cost of crawling as well as the inherent expense of mucus production can be substantial (Calow 1974, Kofoed 1975b, Houlihan \& Innes 1982). Oxygen consumption increases linearly with crawling speed in 4 species of intertidal gastropods (Houlihan \& Innes 1982). Losses via mucus secretions represent 13 to $32 \%$ of energy absorbed in 2 species of freshwater pulmonate snails (Calow 1974), and in the prosobranch Hydrobia ventrosa $9 \%$ of assimilated carbon is excreted as mucus (Kofoed 1975b).

Hydrobia truncata Vanatta (1924) is a small (2 to $5 \mathrm{~mm}$ ) deposit-feeding gastropod. Like other Hydrobia species, $H$. truncata feeds mainly on benthic diatoms (Fenchel et al. 1975, Kofoed 1975a, Fenchel \& Kofoed 1976, Lopez \& Levinton 1978, Jensen \& Siegismund 1980, Levinton \& Bianchi 1981, Bianchi \& Levinton $1984)$ and is often a dominant inhabitant of intertidal mudflats. Often found in densities of 10 to 40000 snails $\mathrm{m}^{-2}$, this animal may frequently encounter patches in which food resources are at least temporarily depleted (Levinton \& Bianchi 1981). Hydrobia species are able to selectively ingest diatoms from the ambient sedi- 
ment either by scraping particle surfaces of their encrusting diatoms (Lopez \& Kofoed 1980), or by handling large diatoms as individual food particles (Fenchel \& Kofoed 1976). It is not known whether this mobile deposit feeder can further enrich its diet by seeking out food-rich patches of sediment in which to preferentially feed.

In order for deposit feeders to survive on a sedimentary matrix that is mostly undigestible, they must process huge quantities of sediment. A result of this activity is that material is successively pelletized and reprocessed. Coprophagy is common among marine invertebrates (Frankenberg \& Smith 1967), and as a consequence of selective ingestion, fecal pellets may actually be sites of local enrichment of food (Newell 1965, Lopez \& Levinton 1978). Hydrobia ventrosa seems to feed normally on its own dismembered fecal pellets (Lopez \& Levinton 1978); however, our preliminary observations suggested that $H$. truncata could distinguish between freshly egested sediment and sediment that had not recently passed through the gut.

The purpose of these experiments was to test the response of Hydrobia truncata, in terms of crawling rate and feeding rate, to manipulations of sediment patch nutritional quality as measured by chlorophyll-a concentration, and to test $H$. truncata's ability to distinguish between recently egested sediment and sediment that has not been recently processed.

\section{MATERIALS AND METHODS}

\section{General}

Specimens of Hydrobia truncata and sediment were collected from the mudflat surface of Flax Pond, a Spartina salt marsh on the north shore of Long Island, New York. The sediment was sieved to obtain the size fraction $<63 \mu \mathrm{m}$. Microalgal concentration was manipulated by incubating the sediment for at least $2 \mathrm{wk}$ at $15^{\circ} \mathrm{C}$ in either of 2 treatments: (a) $0.2 \mu \mathrm{m}$ filtered unenriched seawater (fsw) in the dark, or (b) $0.2 \mu \mathrm{m}$ filtered enriched seawater (f/2) (Guillard \& Ryther 1962) under ca $5.8 \mathrm{~J} \mathrm{~m}^{-2} \mathrm{~s}^{-1}$ of continuous illumination.

Fluorometric analysis of chlorophyll-a was performed using a Turner Designs Model 10 Fluorometer. Samples were prepared for fluorometric analysis by diluting $0.5 \mathrm{ml}$ sediment slurry with $200 \mathrm{ml}$ fsw and blending at low speed for approximately $1 \mathrm{~min}$. Six $1 \mathrm{ml}$ subsamples were filtered onto $0.45 \mu \mathrm{m}$ Millipore filters and extracted in $90 \%$ acetone overnight. The chlorophyll-a readings were corrected for phaeopigments by acidification, and microalgal concentration was expressed as $\mu \mathrm{g}$ chl-a $(\mathrm{g} \text { dry wt. sed.) })^{-1}$ (Jensen \&
Siegismund 1980). Sediment dry weights were taken as the mean of 5 replicates of sediment slurry weighed on a Cahn microbalance $( \pm 1 \mu \mathrm{g})$.

Patch-selection experiments were designed using fluorescent particles ( 2 to $7 \mu \mathrm{m} ; 1.4$ specific gravity; Radiant Color, Richmond, California) as tracers of the different sediment treatments (Carey \& Lopez 1982). Patches were labeled with either chartreuse, which fluoresces green under blue light excitation, or pink, which fluoresces orange. One snail was placed in each of 6 (35 mm diam.) polystyrene culture dishes and presented with 2 semicircular sediment patches. The $3 \mathrm{~h}$ experiments were monitored by time-lapse video recording. Visual observation indicated that the patches remained coherent for the duration of the experiments. Gut residence time for this species is short $(<1 \mathrm{~h})$ (Lopez \& Cheng 1983), and the snails produce an average of ca 100 pellets $h^{-1}$ at $21^{\circ} \mathrm{C}$ (V.F. pers. obs.). At the end of each experiment, fecal pellets were collected with an $85 \mu \mathrm{m}$ sieve and counted, and time spent on each patch was measured from the video recording. The pellets were then broken apart, the resulting slurry diluted with fsw, and the proportions of each tracer color they contained measured by fluorescence microscopy. Five hundred fluorescent particles were counted at $500 \times$ for each of the 6 replicates. To make a control suspension, a 50:50 mixture of sediment from both offered patches was diluted and the tracer particles counted. The only necessary assumption is that the snails are not selecting one color in preference to another. Reciprocal experiments demonstrated the validity of this assumption. Non-selective ingestion of the fluorescent particles with respect to the sediment is not an assumption of this method. The fluorescent particles are not intended to mimic sediment particles, and selection for these particles with respect to natural sediment will not affect our results.

Since the measured control proportions deviated slightly from the expected 50:50 ratio, particle counts were corrected to account for this deviation. For 2 patches labeled with fluorescent colored particles $\mathrm{A}$ and $B$, respectively,

Corrected Particle Count $\mathrm{A}=$ Measured Particle Count

$$
A \times \frac{\text { Expected Control Proportion A }}{\text { Measured Control Proportion A }}
$$

Corrected Proportion $\mathrm{A}=$

$\frac{\text { Corrected Particle Count } A}{\text { Corrected Particle Counts }(A+B)}$

Fecal pellet counts provided a measure of total egestion rate for each snail. Though in nature, pellets egested in one area may indicate material ingested in another, the fluorescent tracer technique permits clear identification of the source of egested material. Patch- 
specific egestion rate $\left(E R_{p}\right)$ was calculated by the following formula,

$$
\mathrm{ER}_{\mathrm{p}}=\frac{\left(\text { Total Pellets) }\left(\mathrm{P}_{\mathrm{A}}\right)\right.}{\left(\mathrm{T}_{\mathrm{A}}\right) \text { (Total Time) }}
$$

where $\mathrm{P}_{\mathrm{A}}=$ proportion of tracer particles representing Patch $A$ in egested feces; $T_{A}=$ proportion of time spent on Patch A.

Distance crawled was measured by tracing the paths of snails from the video monitor onto a sheet of acetate. The length of the path on each patch divided by the time spent per patch gave an estimate of average crawling rate per patch.

\section{Patch-selection experiments}

Enriched vs unenriched sediment. All patch-selection experiments were performed at $21^{\circ} \mathrm{C}$. Experiments 1 and 2 offered the snails a choice between 2 patches of sediment differing in chlorophyll-a content. Each patch covered an area of $481 \mathrm{~mm}^{2}$. In Experiment 3 , the 2 chlorophyll-a treatments were arranged into 4 patches, each having an area of $240.5 \mathrm{~mm}^{2}$. The chlorophyll-a content of each patch for the first 3 experiments is given in Table 1 . It should be noted that

Table 1. Sediment chl-a concentrations for Experiments 1, 2 , and 3. Concentrations are given as $\mu \mathrm{g}$ chl-a (g dry wt. sed. $)^{-1}$

\begin{tabular}{|lrrr|}
\hline & Expt 1 & Expt 2 & Expt 3 \\
\hline Enriched & 144.03 & 84.66 & 95.88 \\
Unenriched & 69.06 & 44.12 & 39.96 \\
\hline
\end{tabular}

the terms 'enriched' and 'unenriched' denote relative chlorophyll concentrations for each experiment and are not defined by absolute chlorophyll concentration.

Sediment vs disaggregated fecal pellets (DFP). In Experiment 4, a group of approximately 50 snails was allowed to feed on enriched sediment for $3 \mathrm{~d}$. Their pellets were collected, gently disaggregated with a mortar and pestle until they would pass through a $63 \mu \mathrm{m}$ sieve, labeled with fluorescent pigment, and immediately fed to the experimental group.

In Experiment 5, the pellets were disaggregated and then aged in the light for $10 \mathrm{~h}$ at $21^{\circ} \mathrm{C}$ before feeding to the experimental group. The chlorophyll-a content of each patch offered in Experiments 4 and 5 is given in Table 2 .

\section{Egestion rate experiments}

Two experiments were conducted to determine whether patch-specific feeding rate was influenced by
Table 2. Sediment chl-a concentrations for Experiments 4 and 5. Concentrations are given as $\mu \mathrm{g}$ chl-a (g dry wt. sed. $)^{-1}$

\begin{tabular}{|lcc|}
\hline & Expt 4 & Expt 5 \\
\hline Disag. pellets & 62.29 & 101.15 \\
Sediment & 58.81 & 52.52 \\
\hline
\end{tabular}

the order in which patches were encountered. At approximately the same time on consecutive days snails were fed either enriched sediment, unenriched sediment, or disaggregated pellets. After $3 \mathrm{~h}$ pellets were collected and counted.

Enriched vs unenriched sediment. Snails were fed unenriched sediment $\left(45.7 \mu \mathrm{g} \mathrm{chl-} \mathrm{ag}^{-1}\right)$ on Day 1 , enriched sediment (133.7 $\left.\mu \mathrm{g} \mathrm{chl}-\mathrm{a} \mathrm{g}^{-1}\right)$ on Day 2, and unenriched sediment $\left(45.7 \mu \mathrm{g} \mathrm{chl-a} \mathrm{\textrm {g } ^ { - 1 } )}\right.$ on Day 3. For $24 \mathrm{~h}$ preceeding the first measurement, and between measurements 1 and 2, the snails were maintained on unenriched sediment. Between measurements 2 and 3 , the snails were kept in fsw. A summary of the design is given in Table 3.

Table 3. Summary of experimental design for egestion rate experiments on enriched and unenriched sediments

\begin{tabular}{|c|c|c|}
\hline $\begin{array}{l}\text { Egestion rate } \\
\text { measurement }\end{array}$ & Pretreatment & Treatment \\
\hline 1 & Unenriched & Unenriched \\
\hline 2 & Unenriched & Enriched \\
\hline 3 & Starved & Unenriched \\
\hline
\end{tabular}

Sediment vs disaggregated pellets. Ten juveniles and 8 adults were used for this experiment. On Day 1 , half the snails were fed unenriched sediment and half were fed disaggregated pellets; on Day 2 the 2 groups were reversed. Between egestion rate measurements, snails were maintained on unenriched sediment.

Unless otherwise noted, results for the patch selection and egestion rate experiments were analyzed using Wilcoxon's Signed Ranks Test, a non-parametric analysis of variance (Sokal \& Rohlf 1983). Results were considered to be significant if $\mathrm{P} \leq 0.05$.

\section{RESULTS}

\section{Patch selection}

Enriched sediment vs unenriched sediment

Analysis of the pooled data for the first 3 experiments shows that snails fed at similar rates (fecal pellets $\mathrm{h}^{-1}$ ) on enriched and unenriched sediments 
(Fig. 1). Snails crawled less on the enriched sediments (Fig. 2), and therefore spent more time on the enriched than unenriched patches (Fig. 3). There was no correlation between patch-specific egestion rate and patchspecific crawling rate, nor was there any correlation between absolute chlorophyll-a concentration and egestion rate. The total number of pellets produced from a patch was a function of the amount of time spent on the patch (Fig. 4), indicating that the rate of pellet production did not change between treatments or experiments.

In Experiment 1, the snails spent an average of $75 \%$ of their foraging time on the enriched patch, and the mean proportion of enriched tracer particles in their feces $\left(P_{E}\right)$ was 0.70 (Table 4). Feeding rate did not differ between patches. Five out of 6 snails decreased crawling rate on the enriched patch, while 1 snail increased crawling rate on the enriched patch.

In Experiment 2, the snails spent an average of $59 \%$

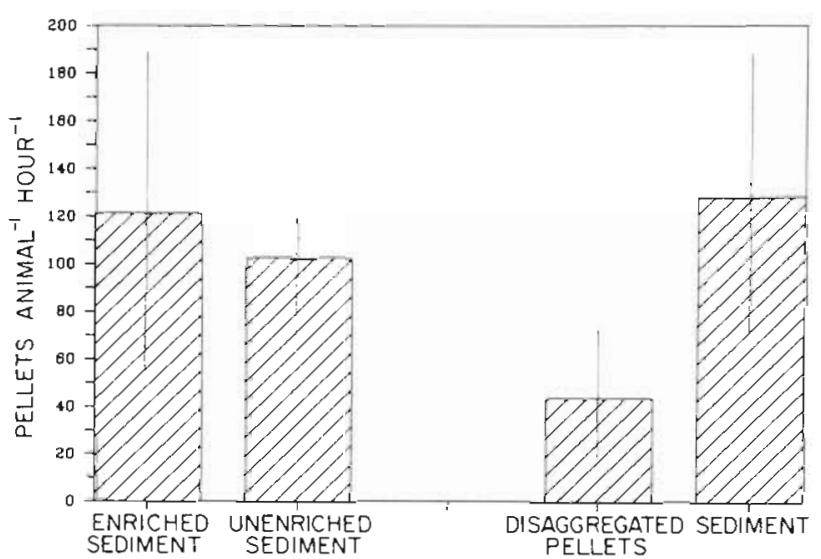

Fig. 1. Hydrobia truncata. Mean patch-specific egestion rates. Results pooled for Experiments 1, 2, and 3 (enriched [ $N=18$ ] $v s$ unenriched [ $N=18]$ ) and Experiments 4 and 5 (sediment $[N=12]$ vs disag. pellets [ $N=12]$ ). Data analyzed using Wilcoxon's Signed Ranks Test (non-parametric). Error bars indicate $95 \%$ confidence limits of the mean

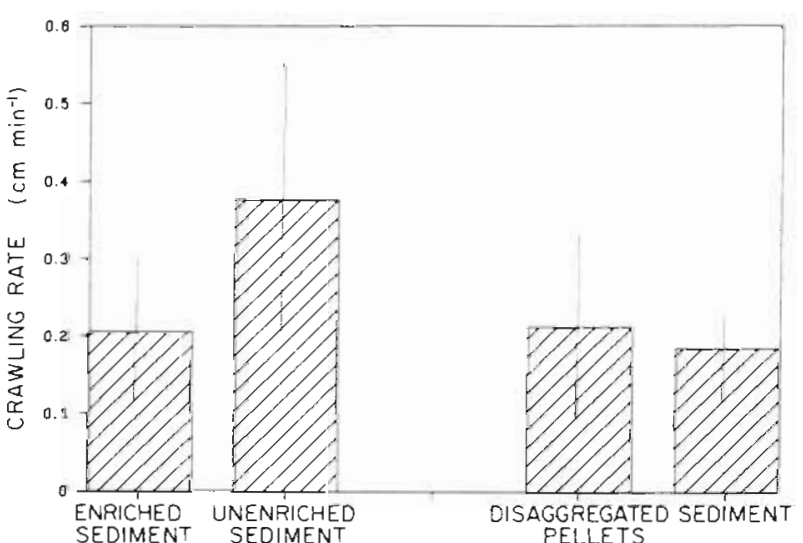

Fig. 2. Hydrobia truncata. Mean patch-specific crawling rates. Results pooled and analyzed as in Fig. 1; $95 \%$ confidence limits of the mean are given of their time on the enriched patch and had a mean $P_{E}$ of 0.68 (Table 4). All snails selected the enriched patch except Snail \# 4. This individual spent only $1 \%$ of its time on the enriched patch and consequently had a

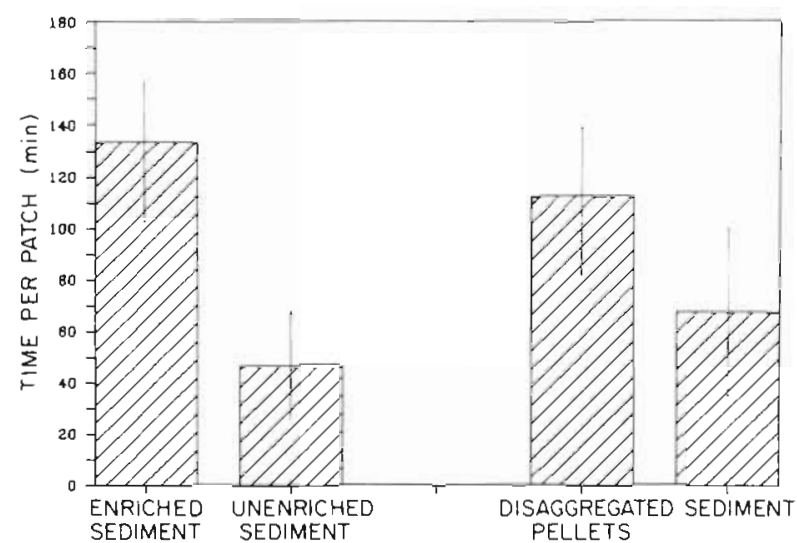

Fig. 3. Hydrobia truncata. Mean time per patch. Number of minutes spent on each patch during a $3 \mathrm{~h}$ experiment. Results pooled and analyzed as in Fig. 1; $95 \%$ confidence limits of the mean are given

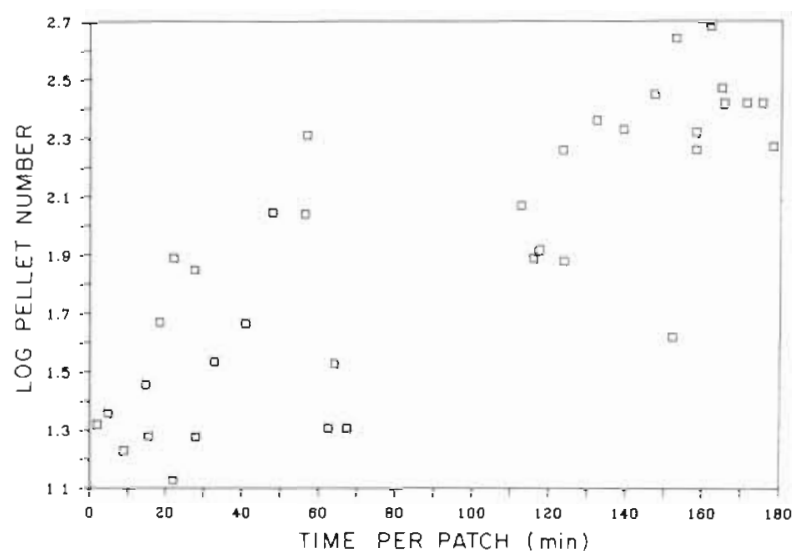

Fig. 4. Hydrobia truncata. Time spent per patch plotted against $\log$ number of pellets produced on each patch for Experiments 1, 2, and $3 . \mathrm{N}=36, \mathrm{r}=0.811, \mathrm{P}<0.001$. principal axis $\mathrm{Y}=1.36+0.006 \mathrm{X}$

Table 4. Hydrobia truncata. Proportion of fluorescent tracer particles marking the enriched patch found in the feces. $0.5=$ no patch selection; $>0.5=$ selection for enriched patch $h_{i}<0.5$ $=$ selection for unenriched patch $(\mathrm{T}$-test on means, $\cdot \mathrm{P} \leq 0.05$. $\cdots P \leq 0.001$ )

\begin{tabular}{|cccc|}
\hline Snail & Expt 1 & Expt 2 & Expt 3 \\
\hline 1 & 0.47 & 0.94 & 0.93 \\
2 & 0.70 & 0.92 & 0.94 \\
3 & 0.69 & 0.67 & 0.90 \\
4 & 0.80 & 0.10 & 0.89 \\
5 & 0.73 & 0.59 & 0.86 \\
6 & 0.82 & 0.85 & 0.91 \\
Mean (SD) & $0.70(0.125)^{\circ}$ & $0.68(0.316)$ & $0.90(0.029)^{\cdots}$ \\
\end{tabular}


very low $\mathrm{P}_{\mathrm{E}}$ of 0.10 . There was no difference in feeding rate between patches. Out of 6 snails, 3 decreased crawling rate, and 3 increased crawling rate on the enriched patch.

In Experiment 3 , the treatments were arranged into 4 small, rather than 2 large, patches. The snails spent an average of $88 \%$ of their time on the enriched patches, and the mean proportion of enriched tracer particles in their feces was 0.90 (Table 4). Feeding rates between patches did not differ. All 6 snails reduced crawling rate on the enriched patches.

\section{Disaggregated pellets vs sediment}

Analysis of pooled results from Experiments 4 and 5 indicates that egestion rate was lower on the disaggregated pellets (Fig. 1). In contrast to results from the first 3 experiments (enriched vs unenriched sediment), crawling rates did not differ between patches (Fig. 2), and there was no difference in the amount of foraging time spent on the disaggregated pellet vs sediment patches (Fig. 3). There was no correlation between the amount of time spent per patch and the number of pellets produced on that patch (Fig. 5), demonstrating that pellet production rate varied between patches.

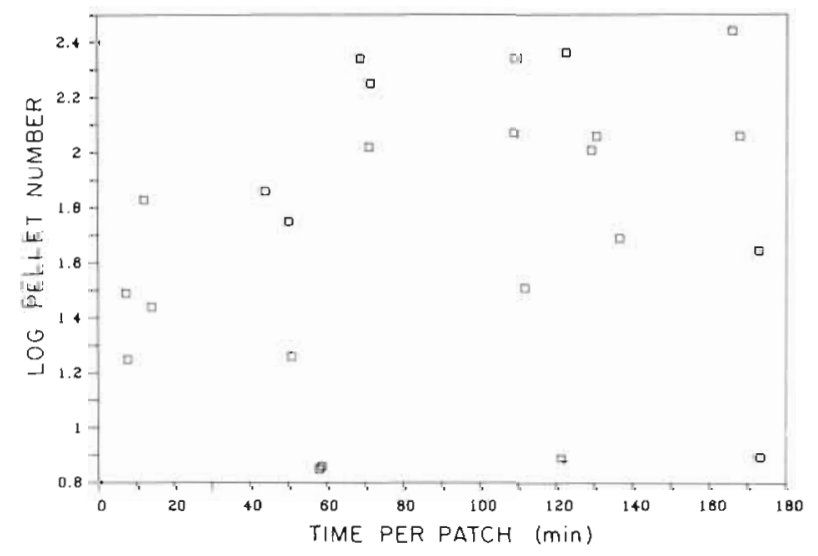

Fig. 5. Hydrobia truncata. Time spent per patch plotted against $\log$ number of pellets produced on each patch for Experiments 4 and $5 . \mathrm{N}=24, \mathrm{r}=0.225, \mathrm{P}>0.05$, principal axis $Y=1.52+0.002 X$

Observations of the videotapes indicate that the large amount of time spent on the disaggregated pellets was partly due to some snails retracting into their shells and becoming inactive upon encounter with patches of this type. Feeding rates on the sediment patches in Experiments 4 and 5 did not differ from those on the sediment treatments in Experiments 1,2 and 3. This suggests that any cue associated with recently egested pellets, which may act to depress feeding, did not readily diffuse into the adjacent sediment.
In Experiment 4, the snails spent an average of $72 \%$ of their time on the disaggregated pellet patch, but the mean proportion of DFP tracer particles in their feces was 0.37 (Table 5). Feeding rates were lower on the disaggregated pellets. Three snails increased crawling rate and 3 snails decreased crawling rate on the DFP patch.

Table 5. Hydrobia truncata. Proportion of fluorescent particles marking the disaggregated pellet patch found in the feces. 0.5 $=$ no patch selection; $>0.5=$ selection for disaggregated pellet patch; $<0.5=$ selection for sediment patch ( $\mathrm{T}$-test on means, $\cdot \mathrm{P} \leq 0.05, \cdots \mathrm{P} \leq 0.001$ ).

\begin{tabular}{ccc|}
\hline Snail & Expt 4 & Expt 5 \\
\hline 1 & 0.63 & 0.53 \\
2 & 0.13 & 0.71 \\
3 & 0.40 & 0.55 \\
4 & 0.03 & 0.33 \\
5 & 0.85 & 0.09 \\
6 & 0.20 & 0.52 \\
Mean (SD) & $0.37(0.317)$ & $0.46(0.216)$ \\
\hline
\end{tabular}

In Experiment 5, in which the DFP patch was also enriched in chlorophyll-a, the snails spent a mean of $53 \%$ of their foraging time on the disaggregated pellet patch. The mean proportion of DFP tracer particles in their feces was 0.46 (Table 5). Feeding rates were similar between patches. Three snails increased crawling rate and 3 snails decreased crawling rate on the disaggregated pellet patch.

\section{Egestion rate experiments}

There was no difference in egestion rate on unenriched sediment between Day 1 and Day 3, nor did egestion rate differ between unenriched and enriched sediment (Fig.6). Twenty-four h of starvation prior to

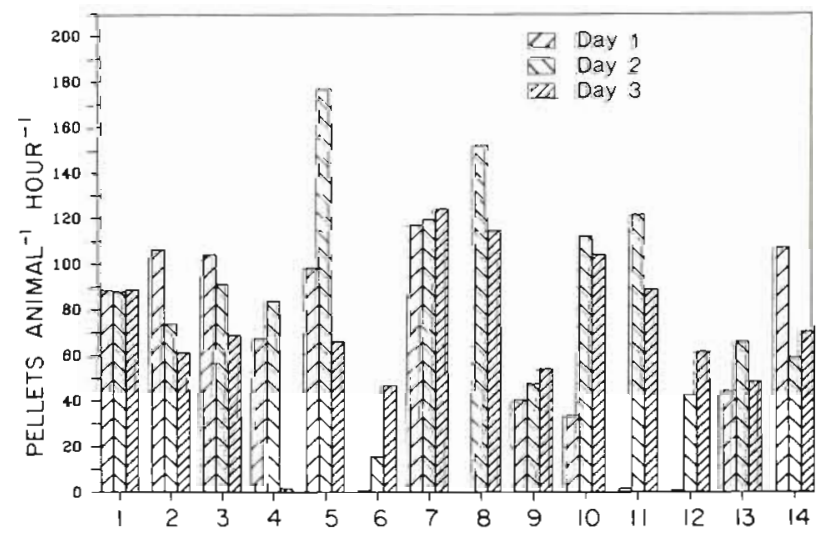

Fig. 6. Hydrobia truncata. Egestion rates of 14 snails fed enriched and unenriched sediments. Day 1: egestion rate on unenriched sediment; Day 2: egestion rate on enriched sediment; Day 3: egestion rate on unenriched sediment 
feeding had no predictable effect on egestion rate There was a great deal of variability in feeding rate between snails for any single sediment type and also within individual snails when sediments are compared. Only 3 out of 14 snails fed at approximately the same rate on unenriched sediment during Days 1 and 3 , but for the other 11, the direction of change in feeding rate between days was not consistent. All snails substantially reduced their egestion rate on artificially disaggregated pellets (Fig. 7)
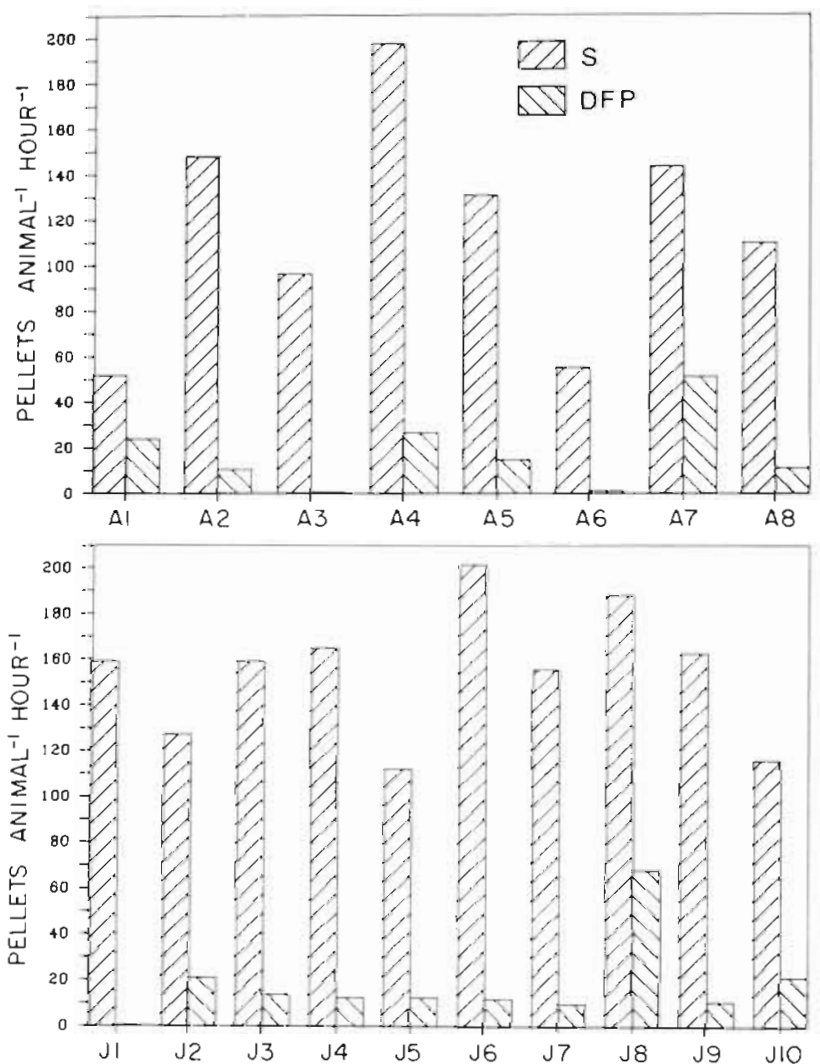

Fig. 7. Hydrobia truncata. Egestion rates of 18 snails fed sediment and artificially disaggregated fecal pellets. S: egestion rate on sediment; DFP: egestion rate on disaggregated pellets; (a) Adults (A1 to A8); (b) juveniles (J1 to J10)

\section{DISCUSSION}

Some deposit feeders alter their feeding rate in response to food quality variations (Calow 1975, Cammen 1980, Taghon \& Jumars 1984). Mobile deposit feeders may respond to changes in food quality without changing feeding rate. Hydrobia truncata decreases its crawling speed while maintaining a constant feeding rate upon encounter with sediment patches relatively rich in chlorophyll-a, thus it spends more time feeding in food-rich patches. Although $H$. truncata is capable of altering its egestion rate, this does not seem to be a direct response to food concen- tration. Reduction in feeding rate by $H$. truncata on recently egested sediment is not a response to depletion of chlorophyll-a. Though most Hydrobia species will rarely feed on their own intact feces (Levinton \& Lopez 1977), H. ventrosa seems to feed normally on its own disaggregated feces (Lopez \& Levinton 1978). The negative response exhibited by $H$. truncata toward disaggregated pellets demonstrates that it is not the physical structure of the pellet that inhibits coprophagy. Rather we suggest that there is a chemical cue, or phagodepressant, associated with feces that inhibits reingestion by $H$. truncata of recently egested material.

It is not clear whether microalgae present in freshly egested pellets would be of any nutritive value to Hydrobia truncata since these microbes have obviously already escaped digestion once. $H$. ventrosa has demonstrated a $40 \%$ digestion efficiency of diatoms from dismembered (i.e. blended) recently egested pellets (Lopez \& Levinton 1978). The authors cautioned, however, that digestion of algae from fecal pellets may have been made possible because blending the pellets detached diatoms from sediment particles and thereby increased their digestibility. In nature, sediments inhabited by Hydrobia spp. tend to be very heavily grazed and may at times be mostly pelletized. This has been shown by Levinton et al. (1977) who developed a model to predict the rates of pellet breakdown in the field, suggesting its important role in making sediment available for reingestion. Levinton \& Lopez (1977) concluded that the rate of pellet breakdown is a limiting step in terms of food availability for Hydrobia spp. Carey \& Lopez (unpubl.) have suggested pellet breakdown times, during the summer, to be roughly $4 \mathrm{~d}$. By the time pellets disintegrate in the field, concurrent dispersion of any phagodepressant may render the pellets indistinguishable from less recently processed sediment. In Experiment 5 in the present study, pellets were aged for $10 \mathrm{~h}$ prior to feeding, and they were also twice as enriched in chlorophyll as the sediment patch they were offered against. The snails did not decrease feeding rate on the DFP patch, as they did in Experiment 4, but neither did they reduce crawling and spend more time feeding on this chlorophyll-rich DFP patch. This may mean that 10 $\mathrm{h}$ of aging is enough to render pellets chemically indistinguishable from sediment, but it is more likely that high chlorophyll-a content may counteract the negative cue associated with recently egested sediment.

The lack of correlation between total pellet production and crawling rate suggests that these components of foraging behavior are under independent control. There were no obvious differences in crawling patterns (i.e. number or direction of turns); however, these were 
not analyzed in detail. We did observe greater proboscidial activity (side to side motion of the head) on enriched patches which may partially explain the lower crawling rates on these patches.

Patch configuration seems to have an effect on patch selection behavior. In Experiments 1 and 2 there were 2 patches offered, while in the third expenment the 2 treatments were arranged into 4 patches with 2 patches per treatment. Although the total area of each treatment remained the same in the 3 experiments, the maximum distance a snail in Experiment 3 would have to crawl before encountering a patch of a different type was decreased. It was in the third experiment that the highest proportion of enriched tracer particles was found in the feces $\left(P_{E}=0.9\right)$, and the largest amount of time was spent on the enriched treatment $(88 \%)$.

There is conflicting evidence for patch selection by other Hydrobia species. Newell (1962) found no difference in the number of $H$. ulvae (after $24 \mathrm{~h}$ ) located on different grades of offered sediment $(>500,>250$, $>125,>62,>37 \mu \mathrm{m}$ ) whether or not $2 \%$ silt was added to each grade. He also found no difference in the number of snails burrowing in each of 5 natural sediment patches taken from different heights on the shore. Fenchel et al. (1975) offered $H$. ulvae patches of sterile sand, sterile sand plus added bacteria, sterile sand plus added diatoms, and natural sand. After 2 to $3 \mathrm{~h}$, they found no difference in the number of snails on each patch. Wells (1978) counted the number of $H$. totteni on patches differing in particle size after $4 \mathrm{~d}$. He found the largest number of snails on the 125 to $250 \mu \mathrm{m}$ fraction, and the least number of snails on the $<63 \mu \mathrm{m}$ fraction. Since the experimental sediments were treated with peroxide to remove organic material, the response was presumably to grain size alone. In laboratory patchselection experiments, Barnes \& Greenwood (1978) measured the preference of $H$. ulvae for different natural sediments by counting the number of snails on each patch after 48 to $66 \mathrm{~h}$. When offered a choice between natural sediments from different localities, the snails preferred the finest of the offered sediments ( $84 \%$ of the particles were $<38 \mu \mathrm{m}$ ) which also had the highest chlorophyll-a content. However, when various size fractions $(<90,90$ to 179,180 to 354 , $>354 \mu \mathrm{m}$; no chl-a values given) of the preferred sediment were offered, the $<90 \mu \mathrm{m}$ fraction was least preferred while the 90 to $179 \mu \mathrm{m}$ fraction was the most preferred. All of these studies determined selection by the presence of an individual in a patch after a given period of time. Our results concerning recently egested sediment demonstrate that the presence of a foraging snail in a patch is not necessarily evidence for patch selection.

We have demonstrated that Hydrobia truncata has the ability to select between patches of sediment in the lab. The snail's response to artificially disaggregated pellets suggests that selection between patches may involve contact chemoreception. How small we can make patches and still retain a response from the snails, and how our patch sizes and configurations relate to those found on a typical mudflat are questions we would in the future like to be able to answer.

Egestion rates of individual snails were found to be highly variable both between different snails feeding on the same sediment and within the same individual feeding on different sediments (Fig. 6 \& 7). Individual variation in feeding has been found for other deposit feeders as well, and probably reflects true physiological differences between organisms (Taghon \& Jumars 1984).

The relation between time spent per patch and total pellets produced (Fig. 4 \& 5) is presented in semi-log form because the log transformation normalized the pellet data and showed the highest correlation with time per patch. This may indicate that as a snail spends more time on a given patch its relative rate of pellet production increases.

In conclusion, Hydrobia truncata can respond to localized patches of high food availability by decreasing its crawling rate and maintaining a constant feeding rate in areas where food is relatively rich. By spending more time in food-rich areas while keeping feeding rate constant, $H$. truncata may be increasing its net rate of energy gain. Feeding rate decreases on disaggregated pellets. In the highly reworked areas that Hydrobia spp. and other deposit feeders inhabit, such recently egested sediment may comprise a large fraction of material available for ingestion. Thus for $H$. truncata, the actual pool of ingestible material may be much reduced.

Acknowledgements. We thank J. Levinton and T. Forbes for discussion and critical comments. L. Kofoed reviewed an earlier draft of this manuscript. E. Cosper and B. Snyder kindly provided the diatom enrichment media and fluorometric assistance. The fluorescent tracer particles were supplied by the Radiant Color Co. This project was funded by NSF Grant No. OCE 8501140 to G. Lopez, and SUNY Graduate Council Fellowship to V. Forbes.

\section{LITERATURE CITED}

Barnes, R. S. K., Greenwood, J. G. (1978). The response of the intertidal gastropod Hydrobia ulvae (Pennant) to sediments of differing particle size. J. exp. mar. Biol. Ecol. 31: 43-54

Bianchi, T. S., Levinton, J. S. (1984). The importance of microalgae, bacteria and particulate organic matter in the somatic growth of Hydrobia totteni. J. mar. Res. 42: $431-443$

Calow, P. (1974). Some observations on locomotory strategies and their metabolic effects in two species of freshwater 
gastropods, Ancylus fluviatilis Mull. and Planorbis contortus Linn. Oecologia (Berl.) 16: 149-161

Calow, P. (1975). Feeding strategies of two freshwater gastropods, Ancylus fluviatilis Mull. and Planorbis contortus Linn. (Pumonata), in terms of ingestion rates and absorption efficiencies. Oecologia (Berl.) 20: 33-49

Cammen, L. M. (1980). Ingestion rate: An empirical model for aquatic deposit-feeders and detritivores. Oecologia (Berl.) 44: 303-310

Carey, D. A., Lopez, G. L. (1982). A new method of estimation of in situ pellet dynamics. EOS (Trans. Am geophys. Un.) 163 (45): 954, 9 Nov. 1982

Fenchel, T., Kofoed, L. H., Lappalainen, A. (1975). Particle size selection of two deposit-feeders: The amphipod Corophium volutator and the prosobranch Hydrobia ulvae. Mar. Biol. 30: 119-128

Fenchel, T., Kofoed, L. H. (1976). Evidence for exploitative interspecific competition in mud snails (Hydrobiidae). Oikos 27: 367-376

Frankenberg, D., Smith, K. L. (1967). Coprophagy in marine animals. Limnol. Oceanogr. 12: 443-450

Guillard, R. R., Ryther, J. H. (1962). Studies of marine planktonic diatoms 1. Cyclotella nana Hustedt, and Detonula confervacea (Cleve) Gran. Can. J. Microbiol. 8: 229-239

Houlihan, D. F., Innes, A. J. (1982). Oxygen consumption, crawling speed, and cost of transport in four Mediterranean intertidal gastropods. J. comp. Physiol. 147: 113-121

Jensen, K. T., Siegismund, H. R. (1980). The importance of diatoms and bacteria in the diet of Hydrobia species. Ophelia (Suppl.) 17: 193-199

Kofoed, L. H. (1975a). The feeding biology of Hydrobia ventrosa (Montagu). I. The assimilation of different components of the food. J. exp. mar. Biol. Ecol. 19: 233-241

Kofoed, L. H. (1975b). The feeding biology of Hydrobia ventrosa (Montagu). II. Allocation of the components of the carbon budget and the significance of the secretion of dissolved organic material. J. exp. mar. Biol. Ecol. 19 243-256

Levinton, J. S., Bianchi, T. S. (1981). Nutrition and food limitation of deposit-feeders. I. The role of microbes in the growth of mud snails (Hydrobiidae). J. mar. Res. 39: $531-545$

Levinton, J. S., Lopez, G. R. (1977). A model of renewable resources and limitation of deposit-feeding benthic populations. Oecologia (Berl.) 31: 177-190

Levinton, J. S., Lopez, G. R., Heidemann Lassen, H., Rahn, U. (1977). Feedback and structure in deposit-feeding marine benthic communities. In: Keegan, B. F., Ceidigh, P. O., Boaden, P. J. S. (ed.) Biology of benthic organisms. Pergamon Press, New York, p. 409-416

Lopez, G. R., Cheng, I.-J. (1983). Synoptic measurements of ingestion rate, ingestion selectivity, and absorption efficiency of natural foods in the deposit-feeding molluscs Nucula annulata (Bivalvia) and Hydrobia totteni (Gastropoda). Mar. Ecol. Prog. Ser. 11: 55-62

Lopez, G. R., Kofoed, L. H. (1980). Epipsammic browsing and deposit-feeding in mud snails (Hydrobiidae). J. mar. Res. 38: 585-599

Lopez, G. R., Levinton, J. S. (1978). The availability of microorganisms attached to sediment particles as food for Hydrobia ventrosa (Montagu) (Gastropoda: Prosobranchia). Oecologia (Berl.) 32: 263-275

Newell, R. C. (1962). Behavioural aspects of the ecology of Peringia (= Hydrobia) ulvae (Pennant) (Gastropoda, Prosobranchia). Proc. Zool. Soc. Lond. 138: 49-75

Newell, R. C. (1965). The role of detritus in the nutrition of two marine deposit feeders, the prosobranch Hydrobia ulvae and the bivalve Macoma balthica. Proc. Zool. Soc. Lond. 144: 25-45

Newell, R. C. (1979). Biology of intertidal organisms. Marine Ecological Surveys Ltd., Faversham, Kent

Robertson, J. R., Bancroft, K., Vermeer, G., Plaisier, K. (1980). Experimental studies on the foraging behavior of the sand fiddler crab Uca pugilator (Bosc, 1802). J. exp. mar. Biol. Ecol. 44: 67-83

Sokal, R. R., Rohlf, F. J. (1983). Biometry, 2nd edn. W H. Freeman and Co., San Francisco

Taghon, G. L., Jumars, P. A. (1984). Variable ingestion rate and its role in optimal foraging behavior of marine deposit-feeders. Ecology 65: 549-558

Vanatta, E. G. (1924). Description of four new American shells. Proc. Acad. nat. Sci. Philad. 76: 25-27

Wells, F. E. (1978). The relationship between environmental variables and the density of the mud snail Hydrobia totteni in a Nova Scotia salt marsh. J. mollusc. Stud. 44: 120-129 